\title{
Der »Bezirk von und um Königsberg«
}

Die Regierungsbezirke Königsberg und Gumbinnen mit Königsberg (13 $200 \mathrm{qkm}$ ) standen vorbehaltlich der endgültigen Regelung der territorialen Fragen durch den Friedensvertrag seit April 1945 unter sowjetischer Verwaltung. In dem neugebildeten Bezirk Kaliningrad in der Russischen Sozialistischen Föderativen Sowjetrepublik lebten 1945 nur noch einige Tausend Deutsche. Das Memelgebiet wurde 1946 der litauischen Sowjetrepublik angeschlossen. Da in Potsdam die Übergabe dieses Gebiets an die Sowjetunion grundsätzlich beschlossen worden war, mußte es als annektiert gelten.

\section{Das polnisch verwaltete Gebiet Ostdeutschlands}

Der Südteil der Provinz Ostpreußen, die Provinzen Grenzmark Posen-Westpreußen, Niederschlesien (auBer dem jenseits der Neiße gelegenen Teil des Regierungsbezirks Liegnitz) und Oberschlesien, die östlichen Teile der Provinzen Pommern und Brandenburg sowie der jenseits der Neiße gelegene Teil des sächsischen Landkreises Zittau (100 651 qkm) wurden nach dem Beschlu $\beta$ von Potsdam, vorbehaltlich der Friedensregelung, polnisch verwaltetes Gebiet. Sechs Woiwod- 